Article

\title{
Lactobacillus and Bifidobacteria Probiotic Strains Improve Glycemic and Inflammation Profiles in Obesity Model in Mice
}

\author{
Lazarenko L.M. ${ }^{1}$, Melnikova O.I. ${ }^{1,2}$, Babenko L.P. ${ }^{1}$, Bubnov R.V. ${ }^{*}$, Beregova T.V. ${ }^{2}$, \\ Falaleyeva T.M. ${ }^{2}$ and Spivak M.Ya. ${ }^{1}$ \\ ${ }^{1}$ D. K. Zabolotny Institute of microbiology and virology, National Academy of Sciences of Ukraine, Kyiv, \\ Ukraine \\ ${ }^{2}$ ESC "Institute of Biology and Medicine" of Taras Shevchenko National University of Kyiv, Kyiv, Ukraine \\ ${ }^{3} \mathrm{LCL}$ 'DIAPROF', Kyiv, Ukraine \\ * Correspondence: dr.rbubnov@gmail.com
}

\begin{abstract}
:
Introduction. The use of probiotics demonstrate efficacy against obesity and metabolic syndrome (MetS). Detection effective probiotic strains for hyperglycemia and immunity associated with is important task.

The aim of the study was to evaluate an influence of Lactobacillus casei IMV B-7280 separately and composition L. casei IMV B-7280 / Bifidobacterium animalis VKB / B. animalis VKL on the levels of blood glucose and immunity in obese mice.

Meterials and methods. Obesity was induced by fat-enriched diet (FED) in male BALB/c mice. Obese mice were transferred to standard diet and received per os probiotic strains daily during 10 days. We measured tumor necrosis factor-a (TNF-a) in blood serum using enzyme-linked immunosorbent assay and functional activity of peritoneal exudate macrophages (PEMs). Glucose levels in blood was defined with glucometer.

Results. We ascertained that all probiotic strains induced reducing mice weight and visceral fat, normalization of TNF-a production and functional activity of PEMs. Treatment with L. casei IMV B-7280 was associated with decreasing blood glucose levels. No normalization of glucose and TNF-a levels in obese mice, transferred to standard diet without probiotic treatment, although we revealed decreasing their weight and visceral fat and partial recover of functional activity of PEMs.

Conclusions. Probiotic strain L. casei IMV B-7280 (separately) and composition L. casei IMV B-7280 / B. animalis VKB / B. animalis VKL can re-equilibrate metabolic and inflammation indices in mouse obesity model. L. casei IMV B-7280 alone was more efficient in decreasing glucose levels than composition of strains.
\end{abstract}

Keywords: metabolic syndrome; diabetes mellitus; obesity; lactobacilli; bifidobacteria; glucose; macrophages; inflammation; mouse model 


\section{Introduction}

Obesity is a major risk factor for the development of type 2 diabetes mellitus (T2DM) and being more than doubled during the last 30 years, is considered to be the most important health problem globally [1-5].

Metabolic syndrome (MetS) is a common, associated with profound violation of metabolic processes in the human body, and include development of diabetes mellitus (DM), cardiovascular (coronary heart disease, atherosclerosis, arterial hypertension) and hepatobiliary diseases (gallstone disease, bile dyskinesia, chronic cholecystitis), pathology of the musculoskeletal system, as well as several types of cancer and premature death [1].

The diagnosis of "metabolic syndrome" can be made if at least three of the following five criteria [2] are met:

- obesity with abdominal fat distribution, determined by an abdominal circumference of over $102 \mathrm{~cm}$ in men or over $88 \mathrm{~cm}$ in women;

- dyslipidemia (increasing Serum triglycerides greater than $150 \mathrm{mg} / \mathrm{dL}$ (>1.7 mmol/L);

- $\quad$ high density lipoprotein (HDL) cholesterol $\leq 40 \mathrm{mg} / \mathrm{dL}$;

- $\quad$ hypertension of $130 / 85 \mathrm{mmHg}$ or more;

- $\quad$ and fasting blood sugar $\geq \mathbf{1 1 0} \mathrm{mg} / \mathrm{dL}$ (5.6 $\mathrm{mmol} / \mathrm{L})$, or type 2 diabetes mellitus (T2DM).

Abdominal obesity most often occurs as a result of increased energy consumption with food, uncontrolled use of nutritional supplements, low levels of physical activity and genetic predisposition. The complex relation of obesity/overweight and DM as well as their associations with the microbiome has been demonstrated [2-5]. Microbiome is highly variable and a very important player mutually related to DM as well as obesity, e.g., weight gain may be also considered as a complication of insulin treatment [5]. Dietary intervention was found to modulate the gut microbiota and improve glucose control in individuals with T2DM [6].

The role of immunity the development of inflammatory processes in diabetes type 1 and 2 and all aspects of metabolic disorders of obesity, have been extensively discussed and different immunity patterns switch on during both diabetes type 1 and 2 during the modification of gut microbiota have been hypothesized [7-10].

Thus, in type 1 diabetes mellitus, the lowered expression of adhesion proteins within the intestinal epithelium favours a greater immune response that may result in destruction of pancreatic $\beta$ cells by CD8+ T-lymphocytes, and increased expression of interleukin(IL)-17, related to autoimmunity [8]. The relationship between lipopolysaccharides (LPS) and the development of T2DM has been observed in some clinical trials [9]. The cytokine-induced inflammatory or acute-phase response hypothesis claims that T2DM and the MetS are associated with proinflammatory cytokine IL-6 and acute-phase reactants such as C-reactive protein [10]. The gut microbiota benefits humans via short-chain fatty acid (SCFA) production from carbohydrate fermentation, and deficiency in SCFA production is associated with T2DM. Targeted restoration of these SCFA producers may present a novel ecological approach for managing T2DM [11].

On the other hand, it has been proven that both the high-fat as well as carbohydrate-rich diet are independent factors causing the reduction of the number of Bacteroidetes and the increase of the 
amount of Firmicutes [12]. The relative raise of Firmicutes in response to a fat-dominant diet has been described in both mice and human observations [12].

The pathophysiological mechanisms of obesity can involve a number of neuroimmunodecrine disorders [13, 14].

The development of chronic systemic inflammation, dysfunction of specific hypothalamic neurons, and activation of the hypothalamic-pituitary-adrenal axis during obesity cause disturbances in the control of body weight in the lipostat system. In obese patients, with the low level of adiponectin, products of leptin and proinflammatory cytokines increase adipocytes of adipose tissue, which in turn activates the production of IL-1 $\beta$, IL- 6 , tumor necrosis factor- $\alpha$ (IFN- $\alpha$ ), interferon- $\gamma$ and chemokines by the cells of the immune system.

Proinflammatory cytokines affect the activity of adipocytes, lipolysis, insulin reaction, glucose metabolism and adipokine production, which results in fat deposition and systemic chronic inflammation $[13,14]$. Activation of proinflammatory cytokines is considered to be the main factor in the development of resistance to insulin and hyperlipidemia [14].

Clinical data originating from several meta-analyses of randomized controlled trials (RCTs) [15-20] confirm that probiotics may have beneficial effects for diabetes, especially for T2DM patients. Consuming probiotics may improve glucose metabolism by a modest degree, with a potentially greater effect when the duration of intervention is $\geq 8$ weeks, or multiple species of probiotics are consumed [15].

The findings by Horvath et al. [18] explain the beneficial effects of probiotics on immune function via increased serum neopterin levels and the production of reactive oxygen species by neutrophils to improve liver function in cirrhosis.

A meta-analysis of RCTs by Jun et al. [19] stated that application of probiotics may decrease the lipid profile indexes, blood pressure, and fasting blood glucose (FBG) in patients with T2DM and can be a new method for lipid profiles and blood pressure management in T2DM [19].

The by Wang et al. [20] concluded that probiotics may have beneficial effects on the reduction of glucose, insulin and $\mathrm{HbA1c}$ for diabetes, especially for T2DM mellitus patients.

The limitations of completed RCTs [15-20] have been notes to be as follows [19,20]: differences in the inclusion criteria and exclusion criteria for patients; different patients with previous disease and treatments were unavailable; most trials with low quality and low Jadad score; pooled date used for analysis, and unavailable individual patients' data. It was suggested that improvement a quality of clinical trials urgently needed and it would require to consider all known potential biases, update the list periodically, and score the trial by multiplying (not adding) the component scores with regard to risks of potential bias to obtain an overall score, etc. [21].

Probiotics have are great potential for many aspects of MetS and immunity [22-25]. Thus, recently we have studied efficacy of use of probiotic for pillar conditions of MetS, namely obesity, dyslipidemia and liver dysfunction, and also for modifying gut microbiota [25] and against glutamate-induced and immune-mediated obesity [12] and the potential for individualized use according to strain-specific probiotic properties has been recently studied [26].

We have previously found that the original probiotic strains of lactic acid bacteria (LAB) and bifidobacteria (Lactobacillus casei IMV B-7280, Bifidobacterium animalis VKB and B. animalis VKL and others), having hypocholesterolemic, immunomodulatory and anti-inflammatory properties [26] 
also demonstrate high levels of antagonistic activity against pathogenic and opportunistic bacteria [27], the resistance to aggressive conditions of the gastrointestinal tract, high or moderate adhesion to the cells of the epithelium of the gastrointestinal mucosa [26] and immunomodulatory properties associated with bacterial wall structure [28].

On different models of experimental obesity in animals it has been proved that they improved the metabolism and modified the intestinal microbiota. The most effective were L. casei IMV B-7280 and composition L. casei IMV B-7280 / B. animalis VKB / B. animalis VKL [14, 25].

The probiotic strain L. casei IMV B-7280 in recent studies demonstrated most pronounced beneficial effect for most applications.

Therefore, we have set this study to in order finalize the puzzle to study effects of mentioned strains against conditions that constitute MetS.

The aim of the study was to evaluate the effect of probiotic strain L. casei IMV B-7280 (separately) and in composition L. casei IMV B-7280 / B. animalis VKB / B. animalis VKL on the level of glucose in blood and also inflammatory response (inflammation) on the experimental obesity in mice, induced by a diet enriched with fats (FED).

\section{Materials and Methods}

Animals

Experimental study was carried out on BALB/c male at the age of 6-8 weeks (17-24 g). Throughout the experiment, animals are kept under standard vivarium conditions, in plastic cells in a separate room at a constant air temperature $\left(20-22^{\circ} \mathrm{C}\right)$. They received a full-fledged meal and had free access to auto-squirrels.

Ethics

The keeping of animals and all manipulations on them have been carried out in accordance with the Law of Ukraine No. 3447-IV "On the Protection of Animals from Cruel Treatment" and the "European Convention for the Protection of Vertebrate Animals Used for Experimental and Scientific Purposes of September 20, 1985", Strasbourg, 1986), and according to the "General Ethical Animal Experiments" (First National Congress on Bioethics, 2001) and "Code of Practice for the Housing and Care of Animals Used in Scientific Procedures" [29].

The experiments have been conducted under using of anesthetics (pentobarbital sodium), and all accessible efforts have been made to minimize animal suffering.

This study has been approved by the ethics committee of institutional review board and Special Academic Council on Doctoral Thesis of D.K. Zabolotny Institute of Microbiology and Virology of the National Academy of Sciences of Ukraine (protocol N 7 issued 03.07.2018).

No human subjects were included to the study.

\section{Bacteria and culture conditions}

We used original probiotic strains of LAB and bifidobacteria - L. casei IMV B-7280, which is deposited in the Depository of Microorganisms of the DK Zabolotny Institute of Microbiology and Virology of National Academy of Sciences of Ukraine, as well as B. animalis VKL and B. animalis 
VKB. The studies were conducted using bacteria freeze dried in Cuddon Freeze Dryer FD1500 (New Zealand). Prior to each experimental study, the activity of these freeze-dried probiotic bacteria was checked by control of their growth on a Man-Rogosa-Sharpe Agar or Bifido Agar medium (Merck, Germany) at $37^{\circ} \mathrm{C}$ during $24-48$ hours.

\section{Design of the experiment}

The experimental model of FED-induced obesity in mice, previously developed by [25], was used in this work. All groups of mice, except the controls, received FED, which included $30 \%$ of fats, $40 \%$ proteins and $30 \%$ carbohydrates. Mice with obesity were injected with L. casei IMV B-7280 (separately) or composition L. casei IMV B-7280 / B. animalis VKB / B. animalis VKL (in a ratio of 2: 1: 1) orally at a dose of $5 \times 10^{6}$ cells. / animal every day during 10 days. To reproduce the rational therapeutic scheme, these mice were transferred to a regular diet.

Mice were divided into 5 groups of 6 animals each: intact mice receiving the regular diet (control) (Group I); mice receiving FED (Group II); mice with obesity, transferred to a regular diet, and were not given probiotic strains (Group III); obese mice transferred to the regular diet that received L. casei IMV B-7280 (group IV) or L. casei IMV B-7280 / B. animalis VKB / B. animalis VKL (V group).

Mice were weighed weekly. The viability of blood from the caudal vein of mice to determine the level of glucose was carried out prior to the beginning of the FED and at 7, 14, 21, 28, 35, 45 and 52 days of observation. Serum was received from the blood, and was stored at $-20{ }^{\circ} \mathrm{C}$ before the experimental studies were performed. At 52 days mice were killed by cervical dislocation after complete anesthesia, visceral fat was removed from the abdominal cavity and weighed.

\section{Glucose measurements}

To determine the blood glucose content, the Glucometer FreeStyle Optium NEO (Abbot Diabetes Care Ltd (England)) was used.

\section{Cytokines production measurements}

The concentration of TNF- $\alpha$ in serum was determined using the enzyme-linked immunosorbent assay (ELISA) using the immunoassay system Thermo Fisher Scientific Inc. (Bender MedSystems $\mathrm{GmbH}$, Austria) according to manufacturer's recommendations and expressed in $\mathrm{pg} / \mathrm{ml}$.

\section{Macrophages harvest}

On the 52 day after the probiotic bacteria injection, a fluid was collected from the peritoneal cavity in mice of all groups that were killed by cervical dislocation after complete anesthesia. The cooled culture medium 199 was injected into the abdominal cavity, and after the soft massage of the abdomen, the abdominal fluid was collected by aspiration. Peritoneal exudate cells were centrifugated three times $10 \mathrm{~min}$ at $400 \times \mathrm{g}$.

The precipitate was then resuspended in a cold culture medium RPMI-1640, which was added to 10 $\%$ fetal calf serum, $50 \mu \mathrm{g} / \mathrm{ml}$ gentamicin and $1 \mathrm{M}$ Hepes. The cell suspension was placed in a $35 \mathrm{~mm}$ culture plate and incubated for 1 hour at $37{ }^{\circ} \mathrm{C}$ in a $\mathrm{CO}_{2}$ incubator. Nonadherent cells have been removed by gently washing three times with warm phosphate buffered saline (PBS). After that, the adherent cells - the peritoneal exudate macrophages (PEMs) were detached from the surface by 
6 of 17

jetting chilled RPMI-1640 into the cells and counted using Goryaev's chamber. A suspension of PEMs was prepared in RPMI-1640 with $10 \%$ fetal calf serum, $50 \mu \mathrm{g} / \mathrm{ml}$ gentamicin and 1M Hepes in a quantity of $5 \times 10^{7}$ cells $/ \mathrm{ml}$.

Respiratory burst and phagocytic activity measurements

Respiratory burst activity (RBA) of PEMs was evaluated using a spontaneous and stimulated nitro-blue tetrazolium (NBT) reduction test [30].

The principle of this method is the restoration of NBT in the PEMs cytoplasm to formazan under the influence of the superoxide anion formed during cell activation. Formazan has the appearance of dark blue granules, the number of which varies depending on the severity of the oxygen explosion. The advantage was given to the cytochemical record of the results, based on the microscopic examination and counting of the percent NBT-positive (formazan-containing) PEMs. Briefly, in a spontaneous NBT test, $100 \mu \mathrm{l}$ suspension of PEMs ( $5 \times 10^{7}$ cells / ml), $100 \mu \mathrm{l}$ of $0.1 \%$ NBT (Sigma, USA) in PBS and $100 \mu \mathrm{l}$ of PBS were applied to the substrate and incubated at $37^{\circ} \mathrm{C}$ for 2 hours in an atmosphere of $5 \% \mathrm{CO}_{2}$. In the stimulated NBT test, $100 \mu \mathrm{l}$ ef suspension of PBS by daily culture of Staphylococcus aureus strain $8325-4$ (inactivated by heating at $57^{\circ} \mathrm{C}$ for $30 \mathrm{~min}$ ) at a concentration of 5 $\mathrm{x} 10^{9}$ cells / $\mathrm{ml}$ was introduced into the PEMs. After cultivation, PEMs was washed twice with PBS, carefully dried, fixed with methanol and stained with $1 \%$ safranin solution. In the field of view of the microscope, 100 or more cells were counted, the percent NBT-positive of PEMs was determined. The difference between the indices of the spontaneous and stimulated NBT test was calculated by the PEMs functional reserve (FR).

The phagocytic activity of PEMs was determined using latex beads (1.1 $\mu \mathrm{m}$, Sigma, USA) microscopically [2]. Briefly, a $100 \mu \mathrm{l}$ suspension of PEMs $\left(5 \times 10^{7}\right.$ cells / $\left.\mathrm{ml}\right)$ and a suspension of latex particles in PBS was applied to the substrate and incubated at $37^{\circ} \mathrm{C}$ for 2 hours in an atmosphere of 5 $\% \mathrm{CO}_{2}$. After that, PEMs was washed twice with PBS, carefully dried, fixed with methanol and stained with Giemsa. A total of 100 or more PEMs were calculated and determined the Phagocytic index (PI) as the number of phagocytic cells (in \%) and phagocytic number (PN) - the average number of latex particles phagocyted by a single PEM (presented in units).

\section{Statistics}

The received digital data was processed using the computer program STATISTICA. The zero hypothesis for the control and experimental groups was checked with non-parametric Kolmogorov-Smirnov test. The data was represented as $\mathrm{M} \pm$ Std.Dev. The difference between the indicators was considered statistically significant at $\mathrm{P}<0.05$.

\section{Results}

At day 7 from the beginning of FED in mice, observed the change in behavioral reactions: mice became sluggish, their response to external stimuli decreased, and the body temperature increased. At the $14^{\text {th }}$ and $21^{\text {st }}$ day, we detected a tendency to increase their weight, however, the difference compared with the values for intact mice (controls) was insignificant (Fig. 1). Weight of mice that consumed FED exceeded normal values $(\mathrm{P}<0.05)$ on average by $3-4 \mathrm{~g}$, starting from 28 days from the beginning of FED and during the entire subsequent follow-up period. We have found that the 
consumption of FED by mice led to the development of alimentary visceral obesity, confirmed by significant accumulation of visceral fat in the abdominal cavity, the mass of which increased by more than by 18 times $(1206.0 \pm 437.4 \mathrm{mg} /$ animal, in control of $64.8 \pm 2.2 \mathrm{mg} /$ animal; $\mathrm{P}<0.05)$ after 52 days. Along with this, the glucose level in blood of obese mice, was observed to be higher than normal at 35, 45 and 52 days of observation in accordance with $7.46 \pm 0.30 ; 8.10 \pm 0.40$ and $8.23 \pm 0.15$ $\mathrm{mmol} / 1(\mathrm{P}<0.05)$, which may indicate the development of mild hyperglycemia. Thus, an increase in the weight of mice as a result of FED consumption was preceded by an increase in blood glucose levels (Fig. 1).
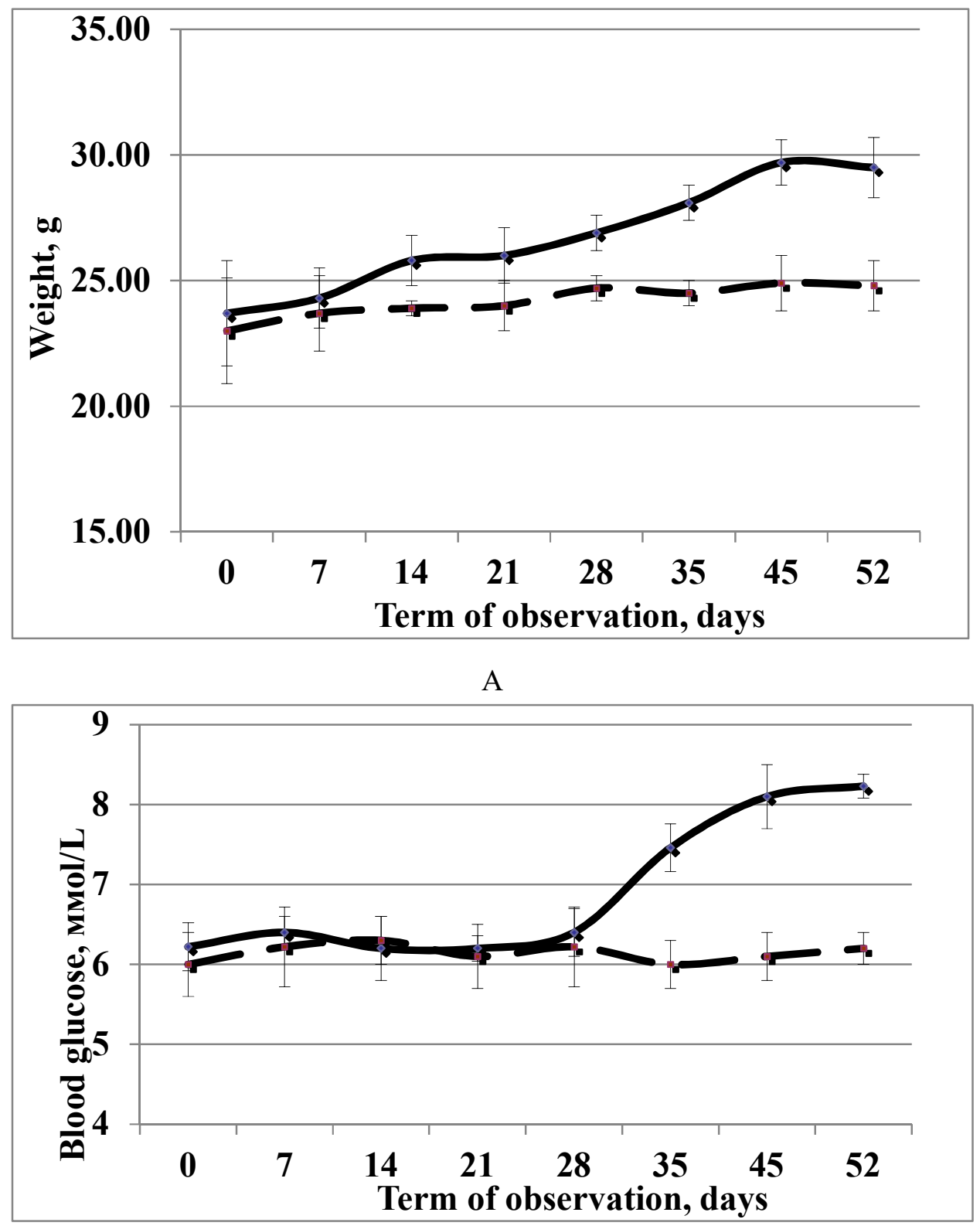

B

Fig. 1. Changes in the weight (A) and glucose (B) levels in the blood of mice receiving FED or a regular diet ( $\mathrm{n}=6$ in each group, $M \pm$ Std.Dev). 1 - intact mice receiving regular diet; 2 - mice receiving FED. 
In the case of injection of L. casei IMV B-7280 (separately) or L. casei IMV B-7280 / B. animalis VKB / B. animalis VKL, the weight of obese mice decreased to the level of control indices, however, there was no probable difference from mice, which continued to consume FED (Table 1). After administration of L. casei IMV B-7280 (separately) or this probiotic composition to obese mice, the weight of the visceral fat was reduced during 52 days according to $366.8 \pm 17.8$ and $343.0 \pm 89.5 \mathrm{mg} / \mathrm{animal}$ relative to the mice, who continued to consume FED $(\mathrm{P}<0.05)$, but remained higher than control $(\mathrm{P}<$ $0.05)$.

Table 1. Weight of obese mice received L. casei IMV B-7280 (separately) and composition $L$. casei IMV B-7280 / B. animalis VKB / B. animalis VKL

\begin{tabular}{|l|c|c|c|c|}
\hline \multirow{2}{*}{ A group of animals } & \multicolumn{3}{|c|}{ Weight of mice, g / period of observation from the beginning } \\
\cline { 2 - 5 } & day 0 & day 35 & day 45 & day 52 \\
\hline Intact mice (controls) & $23.5 \pm 0.1$ & $24.5 \pm 0.9$ & $24.9 \pm 0.8$ & $24.8 \pm 1.0$ \\
\hline $\begin{array}{l}\text { Obese mice that continued to } \\
\text { receive FED }\end{array}$ & $22.0 \pm 0.9$ & $30.5 \pm 1.1 \bullet *$ & $29.7 \pm 1.9 \bullet *$ & $29.5 \pm 1.2 \bullet *$ \\
\hline $\begin{array}{l}\text { Obese mice, transferred to a } \\
\text { regular diet, and did not receive } \\
\text { probiotic bacteria }\end{array}$ & $22.7 \pm 1.1$ & $30.9 \pm 1.1 \bullet *$ & $24.0 \pm 1.1$ & $24.0 \pm 2.0$ \\
\hline $\begin{array}{l}\text { Obese mice, transferred to a } \\
\text { regular diet, that received L. casei } \\
\text { IMV B-7280 }\end{array}$ & $21.5 \pm 0.8$ & $28.9 \pm 0.8 \bullet *$ & $25.3 \pm 1.8$ & $25.4 \pm 2.8$ \\
\hline $\begin{array}{l}\text { Obese mice, transferred to an } \\
\text { regular diet, that received the } \\
\text { probiotic composition }\end{array}$ & $22.9 \pm 1.5$ & $28.5 \pm 0.9 \bullet *$ & $25.3 \pm 1.0$ & $25.0 \pm 1.9$ \\
\hline
\end{tabular}

Notes: • - P $<0.05$ vs indices of intact mice; ${ }^{*}-\mathrm{P}<0.05$ vs parameters before FED (day 0 ).

Note that similar results were obtained when weighing of the visceral fat in mice with obesity, translated into a regular diet, which did not enter probiotic bacteria (Table 1). The weight of the visceral fat in these mice was also higher than vs the controls $(358.0 \pm 65.4 \mathrm{mg} /$ animal, $\mathrm{P}<0.05)$, although it decreased compared with the mice that continued consumimg FED $(\mathrm{P}<0.05)$.

The blood glucose levels were measured as normal only in obese mice injected with L. casei IMV B-7280 (Fig. 2). Under the influence of L. casei IMV B-7280 / B. animalis VKB / B. animalis VKL composition, the blood glucose level in obese mice did not recover to the control level, although there was a tendency to decrease this parameter. Hyperglycemia was stored in obese mice transferred to a regular diet that did not receive probiotic bacteria. Consequently, the transfer of obese mice to the regular diet did not have a significant effect on the level of blood glucose.

Also hyperglycemia in mice with obesity was associated with the development of inflammation at the systemic level: a slight increase in serum TNF- $\alpha$ levels was observed for 35 and 52 days of observation compared to controls (Fig. 2). 

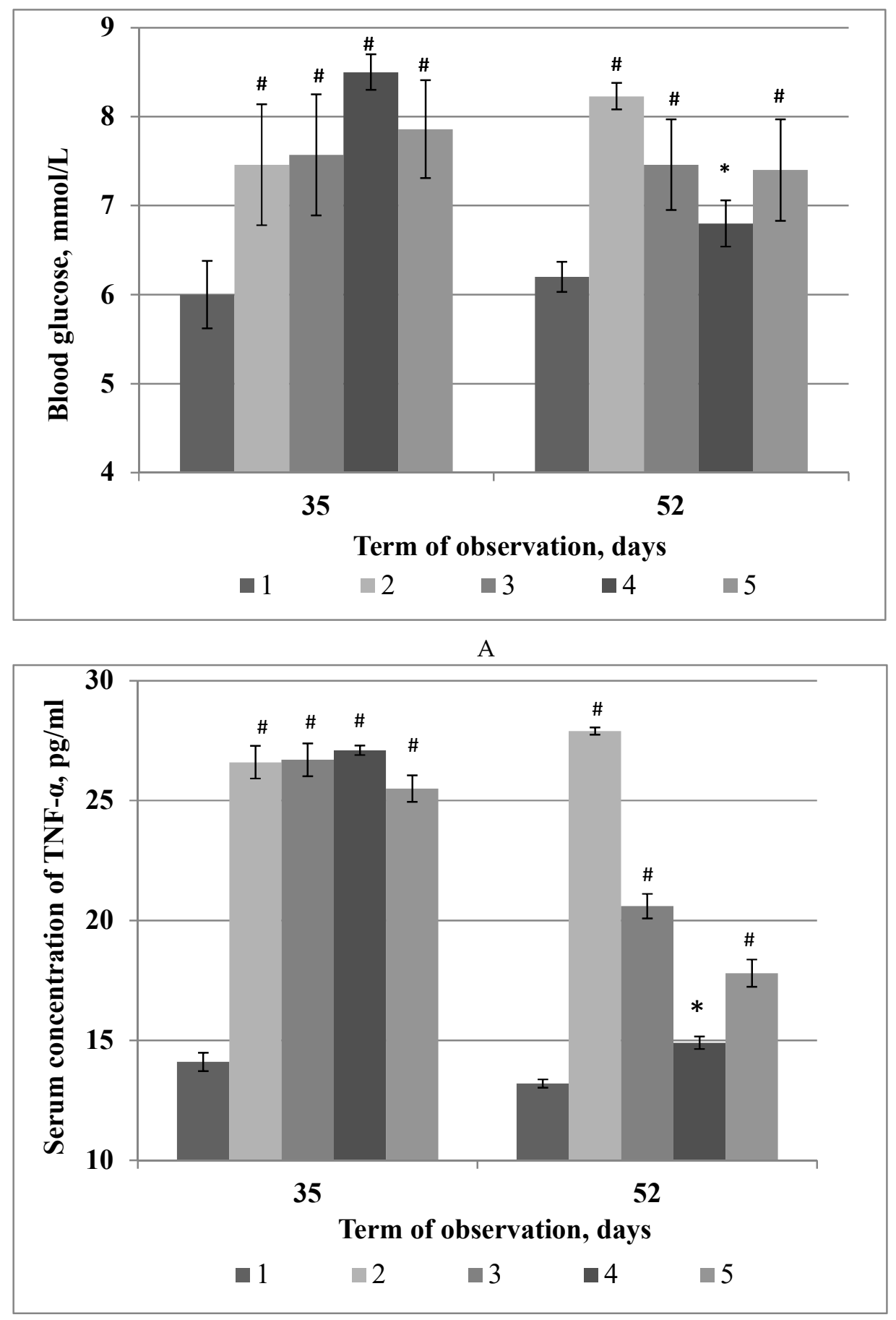

B

Fig. 2. The level of glucose (A) in the blood of obese mice and the levels of serum TNF- $\alpha$ (B) under conditions of administration of probiotic strains $\left(5 \times 10^{6}\right.$ cells / animal) ( $\mathrm{n}=6$ in each group, $\mathrm{M} \pm$ Std.Dev): 1 - intact mice; 2 - obese mice, that continued to receive FED; 3 - obese mice, transferred to an regular diet that did not receive probiotic bacteria ; 4 - obese mice, transferred to an regular diet that received L. casei IMV B-7280; 5 - obese mice, transferred to an regular diet that received L. casei IMV B-7280 / B. animalis VKB / B. animalis VKL composition. \# P $<0.05-$ vs indices of intact mice; ${ }^{*} \mathrm{P}<$ 0.05 - vs indices of obese mice that continued to consume FED. 
The probiotic strain L. casei IMV B-7280 (separate) and the L. casei IMV B-7280 / B. animalis VKB / B. animalis VKL composition demonstrated an antiinflammatory effect in obese mice. So, under conditions of their therapeutic treatment, mice with obesity observed normalization of the serum TNF- $\alpha$ levels (Fig. 2). Instead, in obese mice transferred to the regular diet, without treatment with probiotic bacteria, there was observed a tendency to decrease the levels of TNF- $\alpha$ in serum, but the difference compared to obese mice that continued to consume FED and controls was insignificant. Probably, the reflection of the development of the systemic inflammation to FED-induced obesity in mice we found a hyperactivation of oxygen-dependent bactericidal activity of PEMs against the background of violations of their ability to absorb latex particles and the depletion of reserve capabilities of intracellular systems, which may predispose chronic inflammation and increased sensitivity to the development of infectious and other illnesses.

As it is shown in table 2, the indices of the spontaneous NBT test of PEMs in obese mice increased significantly compared to controls. At the same time, PEMs of these mice did not respond on additional stimulation in vitro, no difference was found between the indices of the spontaneous and stimulated NBT test, there was no FR of the PEMs detected. It should be noted that the hyperproduction of oxidants by activated phagocytic cells, in particular due to the development of inflammation, can lead to an increase in the level of intracellular autooxic processes and inhibition of their functional activity [3]. This might explain a decreasing phagocytic activity of the PEMs in FED-induced obesity in mice according to PI (by $36.5 \%$ ) and to PN (by $62.5 \%$ ) compared with controls. After administration of L. casei IMV B-7280 (separately) or L. casei IMV B-7280 / B. animalis VKB / B. animalis VKL composition, the functional activity of the PEMs was restored to the control values (table 2). Instead, in obese mice transferred to the regular diet that did not receive probiotic bacteria, yet there was a detected the normalization of phagocytic activity of the PEMs, but the NBT test values remained significantly higher than in the control. There was also absent the FR of the PEMs of these mice.

Table 2. PEMs activity in obese mice that received L. casei IMV B-7280 (separately) and L. casei IMV B-7280 / B. animalis VKB / B. animalis VKL composition .

\begin{tabular}{|l|c|c|c|c|c|}
\hline \multirow{2}{*}{ A group of animals } & \multicolumn{5}{|c|}{ Indices of activity of PEMs } \\
\cline { 2 - 6 } & PI, \% & PN, units & $\begin{array}{l}\text { Spontaneous } \\
\text { NST test, \% }\end{array}$ & $\begin{array}{l}\text { Induced NST } \\
\text { test, \% }\end{array}$ & $\begin{array}{l}\text { Functional } \\
\text { reserve } \\
\text { PEMs, units }\end{array}$ \\
\hline of \\
\hline $\begin{array}{l}\text { Intact mice (controls) } \\
\text { receive FED }\end{array}$ & $31.5 \pm 2.6$ & $4.0 \pm 1.0$ & $42.0 \pm 4.3$ & $59.7 \pm 1.5$ & $9.9 \pm 0.3$ \\
\hline $\begin{array}{l}\text { Obese mice, transferred to a } \\
\text { regular diet, and did not } \\
\text { receive probiotic bacteria }\end{array}$ & $30.0 \pm 2.1^{*}$ & $3.8 \pm 0.9^{*}$ & $60.0 \pm 8.0 \bullet$ & $57.0 \pm 10.0$ & 0 \\
\hline $\begin{array}{l}\text { Obese mice, transferred to a } \\
\text { regular diet, that received L. } \\
\text { casei IMV B-7280 }\end{array}$ & $38.0 \pm 4.2^{*}$ & $3.2 \pm 0.1^{*}$ & $34.0 \pm 7.0^{*}$ & $43.0 \pm 5.0^{*}$ & $9.0 \pm 0.0$ \\
\hline
\end{tabular}


11 of 17

\begin{tabular}{|l|l|l|l|l|l|}
\hline $\begin{array}{l}\text { Obese mice, transferred to a } \\
\text { regular diet, that received the } \\
\text { probotic composition }\end{array}$ & $28.0 \pm 3.4^{*}$ & $3.8 \pm 1.0^{*}$ & $32.0 \pm 2.0^{*}$ & $42.0 \pm 9.1^{*}$ & $10.0 \pm 2.0^{*}$ \\
\hline
\end{tabular}

Notes: $\bullet-\mathrm{P}<0.05$ vs indices of intact mice; ${ }^{*}-\mathrm{P}<0.05$ vs indices of obese mice that continued to consume FED.

\section{Discussion}

Thus, the results obtained demonstrate the potentially preventive effect of L. casei IMV B-7280 (separately) and L. casei IMV B-7280 / B. animalis VKB / B. animalis VKL composition on FED-induced obesity in mice. Supplementing the usual diet with probiotic therapy led to a decrease in the weight of obese mice and visceral fat mass against the background of normalization of the production of TNF- $\alpha$ and the functional activity of PEMs. There was a recovery to control values of glucose content in blood of obese mice only after injection of L. casei IMV B-7280.

It has been proven that probiotics based on strains of $\mathrm{LAB}$, representatives of commensal intestinal microbiota, can reduce body weight and improve obesity biomarkers such as hyperglycemia, dyslipidemia and inflammation [31].

According to the literature data, chronic hyperglycemia can trigger lipid peroxidation, decrease the stability of the antioxidant system, and damage the vascular endothelium [32, 33], resulting in increased levels of proinflammatory cytokine, like TNF- $\alpha$ and other markers of systemic inflammation in the blood, as well as the functional activity of macrophages [34-38]. Since the level of TNF- $\alpha$ excretion is characterized by a clear positive correlation with the degree of obesity and insulin resistance, the correction of products of this proinflammatory cytokine is considered by many researchers as a promising therapeutic approach to the treatment of obesity and insulin resistance [34]. This is explained by the fact that increased intestinal permeability due to the disturbance of the intestinal microbiota spectrum enhance penetration of LPS of gram-negative bacteria into the blood, liver and adipose tissue, where they are recognized by the Toll- and NOD-like receptors expressed on macrophages and dendritic cells, activating the innate immune response and initiate the development of inflammation, being involved in the pathophysiology of obesity and the formation of insulin resistance. Increasing the LPS content in the blood for obesity correlated with the activation of products of TNF- $\alpha$ and other proinflammatory cytokines [35].

LPS triggers a strong proinflammatory reaction in colonic macrophages and secretion of proinflammatory cytokines that include TNF- $\alpha$, interferon- $\gamma$, and IL-1 $\beta$, whereas antiinflammatory cytokines IL-10 and IL-17 decrease and restore the intestinal permeability [36].

Commensal microbiota were reported induce hyporesponsiveness to LPS via the production of IL-10 [37]. A randomized controlled clinical trial by Mohamadshahi et al [38] showed that consumption of probiotic yogurt for 8 weeks improved lipid profile in type 2 diabetic patients induced a significant decrease in $\mathrm{HbA} 1 \mathrm{c}$ accompanied by reduction levels of proinflammatory cytokine TNF- $\alpha$.

On the other hand, in current study the normalization of blood glucose and TNF- $\alpha$ production was not observed in obese mice transferred to a regular diet, and not treated with probiotic bacteria, although their weight loss was detected, the weight of the visceral fat reduced, and the partial restoration of the functional activity of PEMs. 
We believe that the change in the spectrum of gastrointestinal microbiota plays a key role in the implementation of the anti-inflammatory action of L. casei IMV B-7280 (separately) and L. casei IMV B-7280 / B. animalis VKB / B. animalis VKL composition for FED-induced obesity in mice. As is well-known, its imbalance, arising from the consumption of a HFD and more often found in the increase in the number of Firmicutes, Proteobacteria and in the reduction of LAB, is also one of the causes of systemic chronic inflammation [39].

Previously, we have found [25] that in the intestinal contents of obese mice receiving L. casei IMV B-7280 (separately) or L. casei IMV B-7280 / B. animalis VKB / B. animalis VKL composition, increased the amount of LAB, bifidobacteria and gram-negative bacteria (colimorphic bacteria), although there was no normalization of the total number of aerobic and facultatively anaerobic bacteria and the number of gram-positive coccus. This is combined with the normalization of lipid metabolism (the level of general and free serum cholesterol decreased while increasing the content of the esophageal protein the cholesterol esterification ratio and the level of normal) and improving the morphological structure of the liver (decreased or disappeared distinct degenerative changes such as necrosis, fatty degeneration of hepatocytes and multiple hemorrhages).. The current data might support the idea of multifactorial mechanism of preventive action of these probiotic strains of bacteria in FED-induced obesity in mice, being in in agreement with broad literature data.

Number of studies demonstrate that other probiotic strains of LAB and bifidobacteria had a strain-dependent therapeutic effect on FED-induced obesity in mice of different genetic lines [40-44]. Thus, the effectiveness of the strains, such as L. acidophilus AD031, B. bifidum BGN4 and B. longum BORI, was reduced by the following: weight of mice (B. longum BORI), triglycerides (B. bifidum BGN4 and L. acidophilus AD031) and total cholesterol (B. longum BORI), as well as morphological manifestations of liver steatosis [40]. Introduction L. acidophilus NS1 to obese mice was due to a decrease in the level of total cholesterol and cholesterol of low density lipoprotein [41], and $L$. acidophilus NCDC was a modification of the composition of the intestinal microbiota [42]. When $L$. plantarum K21 was used in blood plasma of obese mice, the level of leptin, cholesterol and triglycerides decreased; decreased the intensity of liver damage and increased the number of Lactobacillus spp. and Bifidobacterium spp in the gastrointestinal tract [43]. Probiotic strains $L$. curvatus HY7601 and L. plantarum KY1032 prevented fat accumulation in obese mice, reduced their weight, as well as insulin, leptin, and total cholesterol levels in blood plasma, modified intestinal microbiota and suppressed the expression of genes of proinflammatory molecules (TNF- $\alpha$, IL-6, IL-1 $\beta$, etc.) in adipose tissue [44].

It has been shown that Bifidobacterium spp. improved homeostasis of glucose in mice, reduced the levels of accumulation of fat and reduced insulin secretion in FED-induced obesity model. Under the influence of B. breve B-3, the weight of obese mice and the accumulation of visceral fat decreased with a decrease in total cholesterol, glucose and insulin in serum [45]. Following the introduction of C. pseudocatenulatum CECT 7765 obesity mice, changes in expression of key genes involved in regulation of energy metabolism and lipid transport were detected [46].

We have established that probiotic strain L. casei IMV B-728 (separate) and the L. casei IMV B-7280 / B. animalis VKB / B. animalis VKL composition were effective also for glutamate-induced and immune-mediated obesity in Wistar rats [14]. Probiotics prevented growth retardation, reduced body mass index and protected from excessive accumulation of visceral fat. The mechanisms of 
influence of these probiotic bacteria were also: normalization of lipid and carbohydrate metabolism, the state of the antioxidant system and mitigation of inflammation processes. The more effective treatment effect of obesity caused by sodium glutamate was the L. casei IMV B-7280 / B. animalis VKB / B. animalis VKL composition [14], while in FED-induced obesity in mice - L. casei IMV B-7280 (separately), which is probably due to the pathophysiological features of the development of these diverse types of obesity.

\section{Novel insights \& future outlooks}

Recent findings can initiate reconsidering strategies for probiotic therapies.

Thus, according to 'Developmental Origins of Health and Disease' (DOHaD) hypothesis [47] infant microbiota alterations due to colonisation from obese mothers may lead to increased risk of childhood obesity and diabetes [48]. The maternal gut microbiome is the source of the majority of transmitted strains shaping the early microbial diversity in the infant gut [49]. This provides novel insights for earliest prevention of MetS via targetting mother's gut microbiome.

Dead bacteria might also improve diabetic profiles. Thus, the study by Kikuchi et al. [50] indicates that sterilized bifidobacteria suppressed fat accumulation, improved insulin resistance, and lowered blood glucose levels in mice on a high-fat diet.

Current model of obesity may corresponds to MetS model according to the definition [2] and consequently this study completes an agenda on the research strategy for metabolic syndrome treatment with probiotics since studied strains: reduce obesity and visceral fat $[14,25]$, improve dyslipidemia [25], and re-equilibrate glycemic and inflammatory profiles in obesity according to the results of current study.

The "single strain" concept could be preliminary considered, since the probiotic strain L. casei IMB B-7280 has been demonstrated to be most effective in decreasing glucose and serum TNF- $\alpha$ levels than composition of the probiotic strains.

Therefore it is promising for the development of probiotics of multifactorial actions that can be used for the prevention of obesity and personalized treatment of patients with MetS and DM.

On the other hand individualized approach should be carefully considered for personalized dietary and probiotic therapy for obese patients, as well as to set preventive programs, taking into account patient's individual profiles: age, sex, spectrum of intestinal microbiota, immune system status, nutritional habits, etc.

Further research should aim study the effectiveness vs currently established efficacy for the identification of new effective compositions of probiotic strains of bacteria, the selection of optimal treatment schemes and rational dosage.

\section{Conclusions}

Thus, the probiotic strain L. casei IMV B-7280 (separately) and L. casei IMV B-7280 / B. animalis VKB / B. animalis VKL composition under FED-induced obesity in the male BALB / c mice normalized the production of TNF- $\alpha$ and blood glucose (L. casei IMV B-7280), as well as functional activity of the phagocytic cells along with the reduction of their weight and mass of visceral fat.

Probiotic strain L. casei IMV B-7280 was more effective in decreasing glucose than L. casei IMV B-7280 / B. animalis VKB / B. animalis VKL composition strains. 


\author{
Abbreviations \\ fat-enriched diet (FED) \\ functional reserve (FR) \\ high density lipoprotein (HDL) \\ high density lipoprotein (HDL) \\ interleukin (IL) \\ lactic acid bacteria (LAB) \\ lipopolysaccharides (LPS) \\ metabolic syndrome (MetS) \\ nitro-blue tetrazolium (NBT) \\ peritoneal exudate macrophages (PEMs) \\ phagocytic number $(\mathrm{PN})$ \\ phosphate buffered saline (PBS) \\ phagocytic index (PI) \\ respiratory burst activity (RBA) \\ short-chain fatty acid (SCFA) \\ tumor necrosis factor- $\alpha$ (TNF- $\alpha)$ \\ diabetes mellitus (DM) \\ type 2 diabetes mellitus (T2DM) \\ fasting blood glucose (FBG)
}

Author Contributions: LML, MOI and LPB performed the experiments on animals. LML analysis of the study and prepared the first draft of manuscript, did the literature analysis, interpreted the results, and performed the statistical analysis. RVB did the study analysis, prepared discussion, formulated future outlooks, and performed the second and final article drafting. BTV and FTM participated in analysis of the study. MYS and LML suggested the idea, did the organization, revision manuscript and data interpretation, did the contribution to the overall development of the studied topic. All authors read and approved the final manuscript.

Funding: This research received financial support from the State Fund for Fundamental Research of Ukraine via the framework of the project $\Phi 64 / 28-2015$.

Conflicts of Interest: The authors declare no conflict of interest.

\title{
References
}

1. WHO/FAO

scientific

document. http://who.int/foodsafety/fs_management/en/probiotic_guidelines.pdf. Accessed 7 Aug 2018

2. Harsch IA, Konturek PC. The Role of Gut Microbiota in Obesity and Type 2 and Type 1 Diabetes Mellitus: New Insights into "Old" Diseases. Med Sci (Basel). 2018 Apr 17;6(2). pii: E32. doi: $10.3390 /$ medsci6020032.

3. Musso G, Gambino R, Cassader M. Obesity, diabetes, and gut microbiota: the hygiene hypothesis expanded? Diabetes Care. 2010 Oct;33(10):2277-84. doi: 10.2337/dc10-0556.

4. Patterson E, Ryan PM, Cryan JF, Dinan TG, Ross RP, Fitzgerald GF, Stanton C. Gut microbiota, obesity and diabetes. Postgrad Med J. 2016 May;92(1087):286-300. doi: 10.1136/postgradmedj-2015-133285. 
5. Chobot A, Górowska-Kowolik K, Sokołowska M, Jarosz-Chobot P. Obesity and diabetes-Not only a simple link between two epidemics. Diabetes Metab Res Rev. 2018 Jun 21:e3042. doi: 10.1002/dmrr.3042.

6. Houghton D, Hardy T, Stewart C, Errington L, Day CP, Trenell MI, Avery L. Systematic review assessing the effectiveness of dietary intervention on gut microbiota in adults with type 2 diabetes. Diabetologia. 2018 May 12. doi: 10.1007/s00125-018-4632-0.

7. Vaarala O, Atkinson MA, Neu J. The "perfect storm" for type 1 diabetes: the complex interplay between intestinal microbiota, gut permeability, and mucosal immunity. Diabetes. 2008 Oct;57(10):2555-62. doi: 10.2337/db08-0331.

8. Gomes AC, Bueno AA, de Souza RG, Mota JF. Gut microbiota, probiotics and diabetes. Nutr J. 2014 Jun 17;13:60. doi: 10.1186/1475-2891-13-60. Review.

9. Creely SJ, McTernan PG, Kusminski CM, Fisher FM, Da Silva NF, Khanolkar M, Evans M, Harte AL, Kumar S: Lipopolysaccharide activates an innate immune system response in human adipose tissue in obesity and type 2 diabetes. Am J Physiol Endocrinol Metab 2007, 292:E740-E747.

10. Fernández-Real JM, Pickup JC.Innate immunity, insulin resistance and type 2 diabetes. Trends Endocrinol Metab. 2008 Jan;19(1):10-6. DOI: 10.1016/j.tem.2007.10.004

11. Zhao L, Zhang F, Ding X, Wu G, Lam YY, Wang X, Fu H, Xue X, Lu C, et al. Gut bacteria selectively promoted by dietary fibers alleviate type 2 diabetes. Science 2018; 359, 1151-1156. DOI: 10.1126/science.aao5774

12. Zhang M, Yang XJ. Effects of a high fat diet on intestinal microbiota and gastrointestinal diseases. World J Gastroenterol 2016;22(40):8905. doi: 10.3748/wjg.v22.i40.8905

13. Guijarro A, Laviano A, Meguid MM. Hypothalamic integration of immune function and metabolism. Prog Brain Res. 2006;153:367-405. doi: 10.1016/S0079-6123(06)53022-5

14. Savcheniuk OA, Virchenko OV, Falalyeyeva TM, Beregova Tetyana V, Babenko LP, Lazarenko LM, Demchenko OM, Bubnov RV, Spivak MY. The efficacy of probiotics for monosodium glutamate-induced obesity: dietology concerns and opportunities for prevention. EPMA Journal 2014, 5:2. doi: 10.1186/1878-5085-5-2

15. Zhang $\mathrm{Q}, \mathrm{Wu} \mathrm{Y}$, Fei X. Effect of probiotics on glucose metabolism in patients with type 2 diabetes mellitus: a meta-analysis of randomized controlled trials. Medicina (Kaunas). 2016;52(1):28-34. doi: 10.1016/j.medici.2015.11.008.

16. Zhang, Qingqing, Yucheng Wu, and Xiaoqiang Fei. Effect of probiotics on glucose metabolism in patients with type 2 diabetes mellitus: a meta-analysis of randomized controlled trials. Medicina 52.1 (2015): 28-34.

17. Wang X, Juan QF, He YW, Zhuang L, Fang YY, Wang YH. Multiple effects of probiotics on different types of diabetes: a systematic review and meta-analysis of randomized, placebo-controlled trials. J Pediatr Endocrinol Metab. 2017 May 24;30(6):611-622. doi: 10.1515/jpem-2016-0230.

18. Horvath A, Leber B, Schmerboeck B, Tawdrous M, Zettel G, Hartl A, Madl T, Stryeck S, Fuchs D, Lemesch S, Douschan P, Krones E, Spindelboeck W, Durchschein F, Rainer F, Zollner G, Stauber RE, Fickert P, Stiegler P, Stadlbauer V. Randomised clinical trial: the effects of a multispecies probiotic vs. placebo on innate immune function, bacterial translocation and gut permeability in patients with cirrhosis. Aliment Pharmacol Ther. 2016 Nov;44(9):926-935. doi: 10.1111/apt.13788.

19. He J, Zhang F, Han Y. Effect of probiotics on lipid profiles and blood pressure in patients with type 2 diabetes: A meta-analysis of RCTs. Chen. W, ed. Medicine. 2017;96(51):e9166. doi:10.1097/MD.0000000000009166.

20. Wang X, Juan QF, He YW, Zhuang L, Fang YY, Wang YH. Multiple effects of probiotics on different types of diabetes: a systematic review and meta-analysis of randomized, placebo-controlled trials. J Pediatr Endocrinol Metab. 2017 May 24;30(6):611-622. doi: 10.1515/jpem-2016-0230.

21. Berger VW, Alperson SY. A General Framework for the Evaluation of Clinical Trial Quality. Reviews on recent clinical trials. 2009;4(2):79-88. 
22. Hill C, Guarner F, Reid G, Gibson GR, Merenstein DJ, Pot B, Morelli L, Canani RB, Flint HJ, Salminen S, Calder PC, Sanders ME Expert consensus document. The International Scientific Association for Probiotics and Prebiotics consensus statement on the scope and appropriate use of the term probiotic Nat Rev Gastroenterol Hepatol. 2014 Aug; 11(8):506-14.

23. Bubnov RV, Spivak MY, Lazarenko LM, Bomba A, Boyko NV. Probiotics and immunity: provisional role for personalized diets and disease prevention. EPMA J. 2015; 6:14. doi: 10.1186/s13167-015-0036-0.

24. Reid G, Abrahamsson T, Bailey M, Bindels LB, Bubnov R, Ganguli K, Martoni C, O'Neill C, Savignac HM, Stanton C, Ship N, Surette M, Tuohy K, van Hemert S. How do probiotics and prebiotics function at distant sites? Benef Microbes. 2017 Jul 20:1-14. DOI 10.3920/BM2016.0222

25. Bubnov RV, Babenko LP, Lazarenko LM, Mokrozub VV, Demchenko OA, Nechypurenko OV, Spivak MY. Comparative study of probiotic effects of Lactobacillus and Bifidobacteria strains on cholesterol levels, liver morphology and the gut microbiota in obese mice. EPMA J. 2017 Oct 10;8(4):357-376. doi: 10.1007/s13167-017-0117-3.

26. Bubnov RV, Babenko LP, Lazarenko LM, Mokrozub VV, Spivak MY. Specific properties of probiotic strains: relevance and benefits for the host EPMA J 2018. DOI : 10.1007/s13167-018-0132-z

27. Lazarenko LM, Babenko LP, Bubnov RV, Demchenko OM, Zotsenko VM, Boyko NV, et al. Imunobiotics are the novel biotech drugs with antibacterial and Immunomodulatory properties. Mikrobiol Z. 2017; 79(1):66-75. https://doi.org/10.15407/microbiolj79.01

28. Mokrozub VV, Lazarenko LM, Sichel LM, Bubnov RV, Spivak MY. The role of beneficial bacteria wall elasticity in regulating innate immune response. EPMA J. 2015;6:13. doi: 10.1186/s13167-015-0035-1.

29. Home Office. Animals (Scientific Procedures) Act 1986. Code of Practice for the Housing and Care of Animals Used in Scientific Procedures. Available online: http://www.official-documents.gov.uk/document/hc8889/hc01/0107/0107.pdf. accessed 28 July 2018

30. Dubaniewicz A, Hoppe A. The spontaneous and stimulated nitroblue tetrazolium (NBT) tests in mononuclear cells of patients with tuberculosis. Rocz Akad Med Bialymst. 2004;49:252-5.

31. Aggarwal J, Swami G, Kumar M. Probiotics and their Effects on Metabolic Diseases: An Update. J Clin Diagn Res. 2013 Jan;7(1):173-7. doi: 10.7860/JCDR/2012/5004.2701.

32. Góralczyk K, Szymańska J, Szot K, Fisz J, Rość D. Low-level laser irradiation effect on endothelial cells under conditions of hyperglycemia. Lasers Med Sci. 2016 Jul;31(5):825-31. doi: 10.1007/s10103-016-1880-4.

33. Macharia M, Kengne AP, Blackhurst DM, Erasmus RT, Matsha TE. The impact of chronic untreated hyperglycaemia on the long-term stability of paraoxonase 1 (PON1) and antioxidant status in human sera. J Clin Pathol. 2014 Jan;67(1):55-9. doi: 10.1136/jclinpath-2013-201646.

34. Tzanavari T, Giannogonas P, Karalis KP. TNF-alpha and obesity. Curr Dir Autoimmun. 2010;11:145-56. doi: 10.1159/000289203.

35. Dragano NR, Haddad-Tovolli R, Velloso LA. Leptin, Neuroinflammation and Obesity. Front Horm Res. 2017;48:84-96. doi: 10.1159/000452908.

36. Hiippala K, Jouhten H, Ronkainen A, Hartikainen A, Kainulainen V, Jalanka J, Satokari R. The Potential of Gut Commensals in Reinforcing Intestinal Barrier Function and Alleviating Inflammation. Nutrients. 2018 Jul 29;10(8). pii: E988. doi: 10.3390/nu10080988.

37. Ueda Y, Kayama H, Jeon SG, Kusu T, Isaka Y, Rakugi H, Yamamoto M, Takeda K. Commensal microbiota induce LPS hyporesponsiveness in colonic macrophages via the production of IL-10. Int Immunol. 2010 Dec;22(12):953-62. doi: 10.1093/intimm/dxq449.

38. Mohamadshahi M, Veissi M, Haidari F, Javid AZ, Mohammadi F, Shirbeigi E. Effects of probiotic yogurt consumption on lipid profile in type 2 diabetic patients: A randomized controlled clinical trial. J Res Med Sci. 2014 Jun;19(6):531-6.

39. Boulangé CL, Neves AL, Chilloux J, Nicholson JK, Dumas ME. Impact of the gut microbiota on inflammation, obesity, and metabolic disease.Genome Med. 2016 Apr 20;8(1):42. doi: 10.1186/s13073-016-0303-2. 
40. Li Z, Jin H, Oh SY, Ji GE.Anti-obese effects of two Lactobacilli and two Bifidobacteria on ICR mice fed on a high fat diet. Biochem Biophys Res Commun. 2016 Nov 11;480(2):222-227. doi: 10.1016/j.bbrc.2016.10.031.

41. Song M., Park S, Lee H, Min B, Jung S, Park S, Kim E, Oh S. Effect of Lactobacillus acidophilus NS1 on plasma cholesterol levels in diet-induced obese mice. J Dairy Sci. 2015 Mar;98(3):1492-501. doi: 10.3168/jds.2014-8586.

42. Arora T, Anastasovska J, Gibson G, Tuohy K, Sharma RK, Bell J, Frost G. Effect of Lactobacillus acidophilus NCDC 13 supplementation on the progression of obesity in diet-induced obese mice. Br J Nutr. 2012 Oct 28;108(8):1382-9. doi: 10.1017/S0007114511006957.

43. Wu CC, Weng WL, Lai WL, Tsai HP, Liu WH, Lee MH, Tsai YC. Effect of Lactobacillus plantarum Strain K21 on High-Fat Diet-Fed Obese Mice. Evid Based Complement Alternat Med. 2015;2015:391767. doi: 10.1155/2015/391767.

44. Park DY, Ahn YT, Park SH, Huh CS, Yoo SR, Yu R, Sung MK, McGregor RA, Choi MS. Supplementation of Lactobacillus curvatus HY7601 and Lactobacillus plantarum KY1032 in diet-induced obese mice is associated with gut microbial changes and reduction in obesity. PLoS One. 2013;8(3):e59470. doi: 10.1371/journal.pone.0059470.

45. Kondo S, Xiao JZ, Satoh T, Odamaki T, Takahashi S, Sugahara H, Yaeshima T, Iwatsuki K, Kamei A, Abe K. Antiobesity effects of Bifidobacterium breve strain B-3 supplementation in a mouse model with high-fat diet-induced obesity. Biosci Biotechnol Biochem. 2010;74(8):1656-61.

46. Moya-Pérez A., Romo-Vaquero M., Tomás-Barberán F., Sanz Y, García-Conesa MT. Hepatic molecular responses to Bifidobacterium pseudocatenulatum CECT 7765 in a mouse model of diet-induced obesity. Nutr Metab Cardiovasc Dis. 2014 Jan;24(1):57-64. doi: 10.1016/j.numecd.2013.04.011.

47. Wadhwa PD, Buss C, Entringer S, Swanson JM. Developmental Origins of Health and Disease: Brief History of the Approach and Current Focus on Epigenetic Mechanisms. Seminars in reproductive medicine. 2009;27(5):358-368. doi:10.1055/s-0029-1237424.

48. Soderborg TK, Borengasser SJ, Barbour LA, Friedman JE. Microbial transmission from mothers with obesity or diabetes to infants: an innovative opportunity to interrupt a vicious cycle. Diabetologia. 2016 May;59(5):895-906. doi: 10.1007/s00125-016-3880-0.

49. Ferretti P, Pasolli E, Tett A, Asnicar F, Gorfer V, Fedi S, Armanini F, t al. Mother-to-Infant Microbial Transmission from Different Body Sites Shapes the Developing Infant Gut Microbiome. Cell Host Microbe. 2018 Jul 11;24(1):133-145.e5. doi: 10.1016/j.chom.2018.06.005.

50. Kikuchi K, Ben Othman M, Sakamoto K. Sterilized bifidobacteria suppressed fat accumulation and blood glucose level. Biochem Biophys Res Commun. 2018 Jul 2;501(4):1041-1047. doi: 10.1016/j.bbrc.2018.05.105. 